\title{
Realism Detranscendentalized
}

\author{
José L. Zalabardo
}

1.

In recent years, several philosophers have advocated views that they see as occupying a middle ground between anti-realism and traditional forms of realism. They are realist views, insofar as they reject anti-realist construals of semantic notions in terms of belief or other human attitudes, but they also reject the positive metaphysical theses with which realism has been traditionally associated.

Donald Davidson has recently come to see his approach to semantic notions as occupying this middle ground. In his Dewey Lectures, he expresses regret at having advertised his position as a brand of realism. He thinks that the term was ill chosen. It suggests 'the positive endorsement of a position, or an assumption that there is a clear positive thesis to be adopted', ${ }^{1}$ whereas his approach to semantic notions only entails a negative thesis: 'The only legitimate reason I had for calling my position a form of realism', he writes, 'was to reject positions like Dummett's antirealism'. ${ }^{2}$ Davidson combines this negative thesis with a no less emphatic rejection of the metaphysical picture of traditional realism. He writes:

I might be tempted to go along with Dummett if I thought we must choose between what Putnam calls transcendental realism [...] and Dummett's identification of truth with warranted assertability, since I find the former view [...] incomprehensible, while I find Dummett's view merely false. But I see no reason to suppose that realism and antirealism, explained in terms of the radically nonepistemic or the radically epistemic character of truth, are the only ways to give substance to a theory of truth or meaning. ${ }^{3}$

Hilary Putnam's current views offer another instance of this attitude. In his own Dewey Lectures, he characterises his philosophical development over the last two decades as 'a long journey from realism back to realism (but not [...] back to the metaphysical version of realism with which I started)' ${ }^{4}$ The form of realism that he now endorses shares with Davidson's position the aspiration to reject both anti-realism and the substantive metaphysical claims of realism.

The availability of this middle position is problematic. What stands in its way is, in Putnam's words,

the all too seductive assumption that we know what the philosophical 
options are, and that they amount in each case to a forced choice between a funny metaphysical something standing behind our talk (whether it be talk of 'truth' or 'reference' or 'necessity' or 'understanding') and 'tough minded' reductionism (verificationism, or deflationism, or antirealism, or whatever) ${ }^{5}$

There is no doubt that this assumption is responsible for a good deal of the appeal of each of the options from which we take ourselves to be forced to choose. For a major advantage of each of them is that it enables us to avoid the other alternative. But the assumption is not gratuitous, as the two options, in their various forms, seem to occupy the whole logical space. Thus, writing about mathematical necessity, Putnam complains that

[b]oth sides in the debate between 'realists' and 'antirealists' [. . .] believe that we are confronted with a forced choice between saying either (1) that there is something besides our practices [...] which underlies those practices [...]; or (2) that there is nothing but what we say and do [.. . . ${ }^{6}$

For Putnam, 'it is a mistake to choose either the 'something besides' or the 'nothing but' horn of the dilemma', ${ }^{7}$ but it is hard to see how a description of the relevant practices could fail to involve a commitment, explicit or implicit, to one of these options.

John McDowell has offered the most elaborate discussion of how an account of semantic notions could transcend this dilemma. He claims to find in Wittgenstein an approach to semantic notions that is genuinely distinct from both anti-realist and extreme realist accounts. Anti-realists, in McDowell's characterisation, reject the idea that understanding of a predicate is grasp of a ratification-independent pattern of application of the predicate, while extreme realists construe understanding of a predicate as grasp of a pattern of application of the predicate that extends of itself to new cases. The position that McDowell finds in Wittgenstein differs from anti-realism in treating understanding as grasp of ratification-independent patterns, and from extreme realism in rejecting the idea that these patterns extend of themselves to new cases. ${ }^{8}$

The assumption that Putnam blames for the impression that a middle position is not available is just as seductive in this case. Both anti-realists and extreme realists can be expected to invoke it (with different emphases) in support of their respective positions. Anti-realists will contend that patterns of application have to be made dependent on the outcome of our investigations because this is the only way to avoid the postulation of patterns that extend of themselves to new cases. And extreme realists will endorse this postulation as the only way of vindicating the independence of patterns of application from the outcome of our investigations.

My goal in this paper will be to develop a framework in which a position along the lines of McDowell's Wittgensteinian view can start to look both intelligible and appealing. I shall extract the main ingredients of this framework from McDowell's work, but I shall not try to decide whether he would endorse the resulting position. 
2.

In 'Wittgenstein on Following a Rule' (1984), John McDowell takes issue with Crispin Wright's reading of Wittgenstein's rule-following considerations. ${ }^{9}$ According to McDowell, the account of semantic notions that Wright extracts from Wittgenstein's work is neither correct nor Wittgensteinian. At the heart of McDowell's disagreement with Wright is a picture of our linguistic practices that, McDowell tells us, Wright finds in Wittgenstein. McDowell characterises in the following terms Wright's picture of our practice of ascribing predicates to objects:

[. . .] human beings vocalizing in certain ways in response to objects, with this behaviour (no doubt) accompanied by such 'inner' phenomena as feelings of constraint, or convictions of the rightness of what they are saying. There are presumably correspondences in the propensities of fellow members of a linguistic community to vocalize, and to feel comfortable in doing so, which are unsurprising in the light of their belonging to a single species, together with similarities in the training that gave them the propensities. But at the basic level there is no question of shared commitments - of the behaviour, and the associated aspects of the stream of consciousness, being subject to the authority of anything outside themselves. ${ }^{10}$

On the face of it, there is an important connection between Wright's picture and the nature of facts about predicate satisfaction. For Wright's picture appears to be incompatible with a thesis concerning these facts for which I shall use the label realism:

There are facts about predicate satisfaction which are not reducible to our inclinations to apply predicates to some objects and not to others.

Thus, if we accept Wright's picture, we seem forced to abandon realism, in this sense, and to choose between rejecting satisfaction facts and treating them as reducible to speakers' inclinations. According to the first option, to which I shall refer as eliminativism, it is wrong to think that there are facts about which objects satisfy, say, the predicate 'square'. Our linguistic training and innate propensities make us feel inclined to ascribe the predicate to some objects and not to others, but there are no facts for these inclinations to track, with respect to which we could speak of our verdicts as correct or incorrect. According to the second option, satisfaction facts would have to be vindicated with the kind of anti-realist construal in terms of speakers' inclinations that McDowell portrays Wright as advocating. Whether an object satisfies the predicate 'square' would be determined by whether the linguistic community feels inclined to apply the predicate to the object, and the verdicts of individual speakers would be correct or incorrect according to whether they agree with the verdicts that secure communal consensus. 
Conversely, saving realism seems to require rejecting Wright's picture of our predicative practice. For in order to maintain that there are satisfaction facts that are not reducible to speakers' inclinations, we seem forced to postulate an 'authority' external to these inclinations with respect to which they can be described as correct or incorrect. And this external authority is explicitly excluded by Wright's picture.

A very natural strategy for bringing this external authority into the picture consists in assigning the job to properties and their instantiation conditions. On this account, each predicate suitable for the task of representing the world would be connected with a property in such a way that the satisfaction conditions of the former are determined by the instantiation conditions of the latter. Thus whether the predicate 'square' is satisfied by an object would be determined by whether the object instantiates the property with which the predicate is connected. I shall refer to this position as platonism.

Notice that the speakers' propensities to linguistic behaviour and the associated conscious episodes, which figure in Wright's picture, could still play an important role in the platonist account. For they are the most likely candidates for the job of effecting the connection between predicates and properties that platonism postulates. One could claim, on the one hand, that the predicate-property pairings are brought about in conscious episodes in which the speaker assigns to a predicate a property that comes before his mind. On the other hand, one could argue that the property that determines the satisfaction conditions of a predicate, as meant by a speaker, is singled out by the speaker's dispositions concerning the application of the predicate. ${ }^{11}$

These considerations yield a map of possible approaches to predicate satisfaction according to which there are only three possible options. Either we reject satisfaction facts, or we reduce them to speakers' inclinations, or we construe them in terms of the external authority provided by properties or other sorting items. McDowell portrays Wright as endorsing the second option, but where does his own position fit in this picture? It is clear that he doesn't want to embrace the eliminativist option. Satisfaction is, in his view, far from illusory. 'Understanding', he writes, 'is grasp of patterns that extend to new cases independently of our ratification, as required for meaning to be other than an illusion'. ${ }^{12}$ In its applications of the predicate 'yellow', 'the community "goes right or wrong" [. . . ] according to whether the object in question is, or is not, yellow" ${ }^{13}$ His attitude to anti-realism is no less hostile. He rejects Wright's attempt to construe satisfaction facts in terms of speakers inclinations, as he finds the resulting picture indistinguishable 'from one according to which the possibility of going out of step with our fellows gives us the illusion of being subject to norms, and consequently the illusion of entertaining and expressing meanings' ${ }^{14}$ For McDowell, Wright fails in his attempt to salvage the notion of satisfaction in a 'purified' or 'etiolated' form, purged of the platonist appeal to an external authority. The reason is that '[i]t is problematic [. . .] whether the picture of the basic level, once entertained as such, can be prevented from purporting to contain the real truth about linguistic behaviour'. ${ }^{15}$ This picture 'irresistibly claims primacy, leaving 
our openness to correction by our fellows looking like, at best, an explanation of our propensity to the illusion that we are subject to norms'. ${ }^{16}$

But McDowell is also opposed to the platonist picture. He rejects the attempt to construe semantic notions by reference to standards external to the practice, as he accepts that Wittgenstein's arguments successfully undermine 'the thesis that possession of a concept is grasp of a pattern of application that extends of itself to new cases' ${ }^{17}$ His attitude to Wright's picture is markedly different from the platonist's. The platonist would reject the picture as an incomplete characterisation of the facts that underlie our predicative practice, as it fails to register all the facts among which semantic facts are to be found. For the platonist, in addition to displaying behavioural propensities and the associated conscious episodes, speakers establish a connection between predicates and properties from which predicates obtain their satisfaction conditions.

McDowell too rejects Wright's picture, but the grounds for his rejection appear totally different from these. For McDowell, the problem with Wright's picture is that it 'can be, at the very best, an attempt to say something that cannot be said but only shown' ${ }^{18}$ Moreover, he would see some merit in it when conceived in this light. ${ }^{19}$ In fact, McDowell seems as close to accepting Wright's picture as would be allowed by the ineffability of the thought that it expresses. In reading Wittgenstein, McDowell tells us, 'it is difficult [...] to avoid acquiring a sense of what, as it were, lies down there: a web of facts about behaviour and "inner" episodes, describable without using the notion of meaning, ${ }^{20}$ i.e. precisely the kinds of fact that figure in Wright's picture.

McDowell sees himself as occupying 'a middle position', ${ }^{21}$ different, on the one hand, from platonism, which 'takes meaning to be wholly autonomous', ${ }^{22}$ and, on the other, from Wright's construal of satisfaction in terms of inclinations and the view that satisfaction is an illusion, into which, he thinks, Wright's position collapses. For McDowell, the rejection of platonism doesn't enjoin the rejection of realism. He doesn't think it necessary to invoke the external constraints that Wright's picture rules out in order to vindicate satisfaction facts that are not reducible to the facts that figure in the picture. According to McDowell, realism is compatible with a certain form of acceptance of Wright's picture.

3.

It is hard to see how the middle ground that McDowell wants to occupy could be a coherent position. Vindicating satisfaction facts seems to require postulating standards that determine which objects satisfy each predicate. And if these standards cannot be found among the behavioural propensities and conscious episodes that figure in Wright's picture, they would have to be imported from elsewhere, as the platonist suggests. The claim that the requisite standards are neither in Wright's picture nor outside of it seems to amount to a straightforward rejection of satisfaction facts. 
But McDowell rejects this entailment, and in 'Wittgenstein on Following a Rule' he offers an account of how we can reject platonism without giving up realism. We have seen that McDowell doesn't object to Wright's picture on the grounds that it offers an incomplete characterisation of the facts that underlie our linguistic practices. He reluctantly accepts the existence of a level 'down there' containing 'nothing but verbal behaviour and (no doubt) feelings of constraint' ${ }^{23}$ The mistake of which he accuses Wright is to identify that level with the level of 'bedrock' - i.e. 'the deepest level at which we may sensibly contemplate the place of language in the world'. ${ }^{24}$ Anti-realists, McDowell tells us, 'locate "bedrock" lower than it is' ${ }^{25}$

Against this, McDowell proposes to "refuse to countenance sub-"bedrock" (meaning-free) characterisations of what meaning something by one's words consists in, and thus respect Wittgenstein's distinction of levels' ${ }^{26}$ Thus, in the Wittgensteinian picture that McDowell puts forward there are two different levels of facts: a lower level, containing nothing but what figures in Wright's picture, and a higher level, in which semantic and other normative facts are to be found. And these two levels are to be kept strictly separate, by refusing to provide reductive construals of semantic and normative notions in terms of the facts that populate the lower level.

Does this picture yield the middle position between anti-realism and platonism for which McDowell strives? There is no doubt that the picture is distinct from anti-realism, as it explicitly rejects the reductive construals with which antirealism proposes to vindicate semantic notions. But its distinctness from platonism is more elusive. One could try to locate the contrast in McDowell's rejection of the platonist's construal of semantic notions. The platonist agrees with McDowell in rejecting reductive construals of semantic notions in terms of the meagre resources of Wright's picture. He construes them instead in terms of facts that Wright's picture fails to register. For the platonist, a complete characterisation of our linguistic practices would register not only behavioural propensities and feelings of constraint, but also the connections with objective standards from which semantic facts emerge. McDowell wouldn't be more sympathetic to this kind of construal of semantic notions than to the kind that anti-realists endorse. But his refusal to entertain construals of semantic notions in terms of the facts of which the platonist avails himself would not suffice for making his position distinct from the platonist's. For the possibility of providing construals of semantic facts in terms of facts of a different kind is not an essential commitment of the platonist position. One could endorse the platonist claim that satisfaction facts emerge from a connection between predicates and standards external to the practice while maintaining that nothing informative can be said about the nature of these standards or of the relation that links predicates with them.

The ensuing version of platonism would be akin to the view that Hartry Field has labelled 'semanticalism', 'the doctrine that there are irreducibly semantic facts'. 27 'The semanticalist claims, in other words,' Field continues, 'that semantic phenomena (such as the fact that "Schnee" refers to snow) must be accepted as primitive, in precisely the way that electromagnetic phenomena are accepted as 
primitive (by those who accept Maxwell's equations and reject the ether) ${ }^{28} \mathrm{On}$ this view, facts about satisfaction would be treated as fundamental components of reality, alongside basic non-semantic facts. Thus, in addition to facts about which objects I feel inclined to apply the predicate 'square' to, there would be facts about which objects satisfy the predicate. The view would be a version of platonism because it would represent the satisfaction conditions of predicates as arising from their association with objective standards, but neither the standards nor the association would be reducible to the other facts that the world contains. ${ }^{29}$

Notice, however, that there is nothing in this position corresponding to McDowell's distinction of levels. The semanticalist platonist would place semantic facts side by side with the facts that inhabit McDowell's basic level. Hence we might be able to construe McDowell's position as distinct from semanticalist platonism by reference to the claim that semantic facts arise at a level above that which contains nothing but verbal behaviour and feelings of constraint. Thus it would be crucial for his claim to have formulated a genuine middle position that some literal sense can be made of this spatial metaphor. One way to cash out the metaphor would be to interpret the claim that the level of semantic facts lies above the level of facts about verbal behaviour and inner episodes as the claim that the reality of the former is entirely dependent on the possibility of construing them in terms of the latter. This is the sense in which a phenomenalist, for example, could say that facts about the physical world arise at a level above that of facts about sense impressions. But clearly this interpretation of the metaphor is not available to McDowell, as it would turn his position into the advocacy of antirealist construals of semantic notions, thus making it collapse into the other extreme that he seeks to avoid. The claim that McDowell's Wittgensteinian position occupies a genuine middle ground between anti-realism and platonism requires a different explanation of the spatial metaphor-one which, I submit, 'Wittgenstein on Following a Rule' fails to provide. I want to suggest, however, that we might be able to plug this gap if we turn our attention to a train of thought that $\mathrm{McD}$ owell has presented elsewhere.

\section{4.}

In 'Anti-Realism and the Epistemology of Understanding' (1981), McDowell characterises his disagreement with Wright as concerning 'the status of a position which is analogous to a kind of idealism, but with linguistic practice in place of "ideas" '. ${ }^{30}$ McDowell sees Wright's reading of Wittgenstein's attack on normativity as standing to his own reading 'as a shallow empirical idealism would stand to an analogous transcendental idealism' ${ }^{31}$ If the absence of normativity from the ground level licenses anti-realism, McDowell tells us, 'then it is a transcendental anti-realism, one which need not clash with the ineradicable necessity of [his brand of realism] in our making sense of ourselves'. ${ }^{32}$

(C) Blackwell Publishers Ltd. 2000 
The picture that emerges provisionally from these passages is one according to which the question of what facts underlie our predicative practice would receive two different, yet compatible, answers depending on whether we adopt the empirical or the transcendental stance. From the 'transcendental' point of view, or the 'cosmic exile's perspective', as McDowell also refers to it, ${ }^{33}$ Wright's picture would be correct. From that point of view, we would see 'nothing but verbal behaviour and feelings of constraint'. But from the 'empirical' point of view, 'from the midst of language as a going concern', 34 normative facts, including facts about satisfaction, would be visible.

But this provisional picture needs to be modified in light of another component of McDowell's combination of empirical realism and transcendental idealism. After drawing the distinction between the empirical and the transcendental points of view, McDowell claims that we cannot adopt the latter. Transcendental truths, he tells us, are 'the sort of thing which shows but cannot be said. For there is no standpoint from which we can give a sense-making characterisation of linguistic practice other than that of immersion in the practice' ${ }^{35}$ We cannot adopt the cosmic exile's perspective because 'we cannot think of the relation between language and reality except from the midst of language as a going concern'. ${ }^{36}$

These categories provide a promising framework for interpreting the middle position between platonism and anti-realism that McDowell advocates. The suggestion is that the middle position should be construed as a combination of empirical realism and transcendental idealism, and that anti-realism should be identified with empirical idealism and platonism with transcendental realism. ${ }^{37}$

For McDowell, anti-realists try to provide a characterisation of our linguistic practices from the transcendental point of view. They oppose the transcendental realist's contention that 'from the cosmic exile's perspective one would be able to discern relations between our language and a realistically conceived world', 38 and substitute 'a different picture of how things would look from that perspective $\mathrm{s}^{39}$ - the picture that contains nothing but verbal behaviour and feelings of constraint. McDowell joins anti-realists in rejecting the transcendental realist's picture of how things look from the cosmic exile's perspective. But instead of providing an alternative account of how things look from that point of view, he urges us 'to set our faces against the idea of the cosmic exile' ${ }^{40}$

The problem for anti-realists is that, since a characterisation of our linguistic practices is, of necessity, a characterisation 'from the midst of language as a going concern', they fail in their attempt to make a transcendental claim. Their characterisation of our linguistic practices is only intelligible as an account of how things look from the empirical perspective. But for McDowell the right thing to say from that point of view is that there are satisfaction facts which are not reducible to speakers' inclinations. Hence, in the only sense in which it is intelligible, the anti-realist characterisation of our linguistic practices is false. In their attempt to express a transcendental truth, anti-realists end up expressing an empirical falsehood. ${ }^{41}$ 
This is not to say that for McDowell the transcendental question of what things would look like from the cosmic exile's point of view is entirely devoid of sense. He seems to admit that there are correct and incorrect answers to this question. Since a correct answer would be a transcendental truth, it is the kind of thing that cannot be said but only shown. From this point of view, the antirealist is no more successful than the transcendental realist in his attempt to say how the question ought to be answered. Nevertheless it seems hard to deny that for McDowell what the anti-realist tries unsuccessfully to say would be the correct answer to the transcendental question, given his tacit acceptance of Wright's picture of the basic level and his decision to characterise his position as a form of transcendental idealism. McDowell's disagreement with Wright concerns how this transcendental truth ought to be expressed. Whereas Wright attempts to say it, McDowell thinks that it can only be shown by our account of our linguistic practices.

We can also understand in terms of these considerations McDowell's attitude towards transcendental realism. For McDowell, transcendental realism is doubly wrong. In trying to characterise our linguistic practices from the cosmic exile's perspective, it attempts to say what cannot be said. Furthermore, that which it attempts to say unsuccessfully is a transcendental falsehood. It is natural to see McDowell's rejection of platonism as resting on the identification of this view with transcendental realism. We have seen that McDowell accepts the empirical version of realism: the picture of our linguistic practices that we get from the midst of language as a going concern contains irreducible semantic facts. But for the transcendental realist these facts arise from relations between our language and a realistically conceived world that we would be able to discern from the cosmic exile's perspective. If platonism is construed as an attempt to chart these relations, McDowell would reject it as a vain attempt to characterise our linguistic practices from the cosmic exile's point of view, and as providing what is, from that perspective, the wrong characterisation. ${ }^{42}$

We can characterise the resulting position in terms of four claims:

(1) We can't describe our linguistic practices from the cosmic exile's point of view.

(2) From the midst of language as a going concern, the right thing to say is that there are semantic facts that are not reducible to our inclinations.

(3) In whatever sense it is intelligible to ask how our practices would look from the cosmic exile's perspective, Wright's picture is the right answer.

(4) Platonism is an account of our predicative practice from the cosmic exile's perspective.

Then McDowell's rejection of anti-realism would be a consequence of (1) and (2), while his rejection of platonism would follow from (3) and (4).

We can interpret in this framework the spatial metaphor of 'Wittgenstein on Following a Rule'. The lower level would correspond to the characterisation of our practices that we would obtain if, per impossibile, we were to adopt the cosmic exile's perspective. The higher level would correspond to the characterisation of 
our linguistic practices from the midst of language as a going concern. Then the contrast between platonism and McDowell's middle position that we found problematic would amount to the contrast between transcendental realism and transcendental idealism. McDowell's middle position would differ from platonism in accepting Wright's picture of our linguistic practices as the right answer to the transcendental question, in whatever sense it can be made intelligible. ${ }^{43}$

But this is only to replace one metaphor with another. We have explained the contrast between bedrock and what lies below in terms of the contrast between the perspective from the midst of language as a going concern and that of the cosmic exile. In order to understand McDowell's combination of empirical realism and transcendental idealism we need to find a less metaphoric characterisation of this contrast. Only then will we be in a position to assess the four claims that I have formulated in terms of McDowell's metaphor.

5.

In order to make some literal sense of the construal of a middle position that I have sketched, we need to start by looking in some detail at certain aspects of our predicative practice that any characterisation of it would have to accommodate. We have seen that our attitude towards Wright's picture of our linguistic practices is likely to affect which approach to satisfaction facts we can adopt. But whether or not we accept Wright's picture, we seem forced to accept an account of how we go about answering satisfaction questions in terms of the facts that Wright places at the basic level. We answer satisfaction questions in accordance with the propensities that we associate with our predicates and the attending feelings of constraint. Those who reject Wright's picture may provide a construal of the conscious episodes in which these propensities are exercised that would not be available to those who accept it. For only the former can portray our feelings of constraint as arising from our conscious interaction with repeatables. But both parties can be expected to accept that engaging in our predicative practice involves answering satisfaction questions in accordance with our propensities.

This suggests that there is an 'operational' level of description of the practice ('a natural history of predication', as Wittgenstein might have put it) that can be expected to be common ground between those who accept Wright's picture and those who reject it. According to this neutral description, we answer satisfaction questions by following the classificatory propensities that we have associated with predicates. When I want to decide whether one of my predicates is satisfied by an object I am confronted with, my verdict will be determined by the propensity that I have associated with the predicate. Sometimes I don't feel inclined to answer either way, but I often do, and when I feel inclined to emit a verdict, the inclination is accompanied by a feeling of constraint, by the impression that the verdict to which I feel inclined is dictated by a commitment that I undertook when I associated the predicate with the propensity that I am now exercising. 
Another neutral feature of the practice is that I often feel inclined to treat a verdict of mine as overriding an earlier one. I may now feel inclined to apply a predicate to an object to which I earlier felt inclined not to apply it, and take this as showing that the earlier verdict was not faithful to the commitment that I undertook when I associated with the predicate the propensity that generates my verdicts on how to apply it. Furthermore, even though I think of the association of a predicate with a propensity as generating a commitment, I sometimes come to the conclusion that no real commitment was generated by one of these associations. On these occasions, I conclude that, contrary to what I used to think, there is no substance to the idea that an application of the predicate can be correct or incorrect.

For many predicates, there is widespread agreement between my inclinations on how to apply them and those of other speakers of the language. Nevertheless, some of the verdicts to which I feel inclined are in conflict with those of the majority. When such disagreements arise, more often than not I let the inclinations of the majority override mine, and conclude that my deviant inclination was not faithful to the commitment that I undertook when I associated the predicate with a propensity. But I don't treat the inclinations of the majority as defining faithfulness to the commitments that I have undertaken. I think that they could be wrong. In fact, we think even of unanimous verdicts as subject to being overridden, and indeed such verdicts are sometimes revised in light of subsequent inclinations.

This neutral characterisation of our predicative practice concerns exclusively the issue of how we go about answering satisfaction questions. It doesn't settle the question of the nature of satisfaction facts, and this is the question on which anti-realists and platonists disagree. The anti-realist feels that his acceptance of Wright's picture forces him to construe satisfaction facts in terms of speakers' inclinations. The platonist agrees that such a construal would be the only way to reconcile satisfaction facts with Wright's picture, and urges us to reject the latter in order to save the irreducibility of satisfaction facts. These may be the only two possible strategies for construing satisfaction facts if Wright's picture of our linguistic practices is incompatible with realism, i.e. with the claim that there are satisfaction facts which are not reducible to our inclinations. Hence the only way to make room for a middle position would be to reject this incompatibility - to maintain that one can accept Wright's picture of our linguistic practices while subscribing to the realist thought. Then we would be able to reject both the antirealist construal of satisfaction in terms of inclinations and the platonist account of the notion in terms of external standards. I am going to argue that Wright's picture is indeed compatible with realism. In fact, I shall contend, the realist thought is a consequence of Wright's picture.

6.

In order to motivate this seemingly paradoxical claim, we need to compare the task of characterising our predicative practice with the task of characterising a

(C) Blackwell Publishers Ltd. 2000 
different practice - one that is structurally identical to ours but is not in any way connected with it. In 'Anti-Realism and the Epistemology of Understanding', McDowell considers a story, due to Michael Dummett, in which Martians attempt to make human linguistic practices comprehensible. ${ }^{44}$ This fantasy enables us to focus on the kind of situation that I want to consider, given the lack of connection between Martian practices and our own. However, it will be better for our purposes to reverse Dummett's story, and consider the situation in which we would find ourselves if we tried to characterise a practice in which Martians engage-one that exhibits all the features that the neutral description ascribes to our predicative practice.

The Martian practice on which I'd like to focus consists in attaching verbal labels to the objects that they encounter. In attaching these labels, Martians follow classificatory propensities that they have associated with each of the labels. When considering whether to attach a label in his repertoire to an object he is confronted with, a Martian often feels inclined either to attach or not to attach the label to the object, and this inclination is accompanied by a feeling of no option-by the impression that the verdict to which he feels inclined is mandated by a commitment that he undertook when he developed the propensity associated with the label.

Normally, when they consider an object several times, they feel inclined to emit the same verdict on each occasion on whether the label should be attached to the object. But occasionally they feel inclined to emit different verdicts on different occasions. Thus one of them may take a second look at an object to which he has previously attached a label and feel that the right thing to do is not to attach it. Sometimes they construe this kind of situation by saying that, even though the label should not be attached to the object now, it was correct to attach it at the time when they felt inclined to do so. But at other times they revise the old verdict in light of the new inclination, concluding that it was never correct to attach the label to the object, and that their earlier inclination to do so was mistaken.

They think that associating a propensity with a label normally brings it about that it makes sense to ask to what objects the label should be attached, but they acknowledge that this connection may occasionally fail-that they may associate a propensity with a label without making it meaningful to ask to which objects the label should be attached. On some occasions, they conclude that this is what happened. A Martian may come to the conclusion that he has been wrong in thinking that it made sense to ask to which objects one should attach a label with which he had associated a propensity.

The Martians have a common repertoire of verbal labels, and they exhibit a remarkable degree of interpersonal agreement in their inclinations concerning which objects each label should be attached to. There are occasional deviations from the communal consensus, but they are treated as indicating that the deviant verdicts are likely to be wrong. Nevertheless, they don't treat communal agreement as defining correctness. They think that they could all be wrong in attaching a label to an object, and they occasionally feel inclined to revise a verdict on which they had previously agreed. 
If we wanted to make sense of the idea that the Martian labelling verdicts can be correct or incorrect, we could take two different general approaches. The first approach would postulate a correspondence between the Martians' verbal labels and features of the objects to which they can be ascribed, and construe their inclinations as correct or incorrect by reference to this correspondence. Thus, their views on whether it makes sense to ask to which objects a label should be applied would be treated as correct or incorrect depending on whether there is a property corresponding to the label. And for those labels which are connected with properties, the Martians' views on whether a label should be attached to an object would be treated as correct or incorrect depending on whether the object exemplifies the property that corresponds to the label.

The second approach would be to try to construe correctness in terms of the verdicts towards which they feel inclined. If we adopted this approach, we could exploit the fact that there is widespread agreement in the verdicts to which they feel inclined and construe correctness in terms of this communal consensus. Then we would be able to speak of individuals' verdicts as correct or incorrect by reference to this communal standard, although the question whether the verdicts that enjoy communal consensus are right or wrong would not have any substantive content.

These approaches to the Martian labelling practice are clearly modelled on the approaches to our predicative practice taken by platonists and anti-realists, and they mirror their respective attitudes to realism and to Wright's picture of our predicative practice. Platonists about the Martian labelling practice manage to treat the correctness of the Martians' labelling verdicts as irreducible to their inclinations, but this is achieved by invoking a connection between labels and properties. Anti-realists about the Martian practice don't invoke any standards external to the Martians' inclinations, but their frugality forces them to construe correctness as reducible to those inclinations.

A middle position concerning the Martian labelling practice would have to combine the anti-realists' frugality with the platonists' respect for realism. It would have to characterise the practice without invoking external standards, solely by reference to the Martians' propensities and feelings of constraint, but treat the correctness of their labelling verdicts as irreducible to these facts. I want to suggest that it is not possible to provide a construal of the Martian labelling practice that satisfies these desiderata. Frugality and realism are incompatible in this case. Nevertheless, it would be wrong to conclude from this that there is no room for the middle position in the case of our predicative practice. I am going to argue that in this case the position is available, but its availability depends crucially on a disanalogy between the task of characterising the Martian labelling practice and that of characterising our predicative practice.

The disanalogy does not concern the character of the practices, but rather the relationship between each of them and the point of view from which we undertake the task of characterising them. In our attempts to characterise the Martian practice, there is no connection between the practice that we are trying to characterise and the practice from which the characterisation emerges. We have, on the 
one hand, the Martian practice of labelling objects, and on the other our own practice of using language for describing the world, including the practices of extraterrestrial communities. But when our goal is to characterise our own predicative practice, the practice that we are trying to characterise is (part of) the very same practice that is supposed to yield the characterisation. I want to suggest that this feature of the latter task opens the way for the thought that realism is not just compatible with frugality, but actually a consequence of it: treating satisfaction facts as irreducible to our inclinations is the only way to do justice to Wright's picture of our predicative practice.

It should be emphasized that I am not claiming that in the case of the Martian labelling practice we have no basis for postulating genuine satisfaction facts - for thinking of their acts of ascribing a label to an object as representing the object as being a certain way. In fact, in light of the parallelisms between the Martian practice and our predicative practice, it would seem reasonable to assume that there is in principle as much reason for postulating satisfaction facts in their case as in our own. My only point in regard to the Martian practice is that in this case the analogues of platonism and anti-realism are the only approaches that we can adopt for construing the practice - independently of whether either construal should be described as involving the postulation of semantic facts. ${ }^{45}$

7.

I have suggested that if we refuse to invoke external standards in our construal of the Martian labelling practice we will have to endorse a Wright-style construal of correctness in terms of the Martians' inclinations, or else reject the idea that it makes sense to speak of their verdicts as correct or incorrect. I am going to argue that in the case of our predicative practice neither of these approaches to satisfaction facts is compatible with Wright's picture of the practice, i.e. that accepting this picture forces us to assert the existence of satisfaction facts which are not reducible to our inclinations.

Let's start by considering Wright's attempt to save satisfaction in the face of his picture of the practice by means of a construal of the notion in terms of our inclinations. According to this construal, there would be some facts concerning our inclinations with regard to a predicate that would make it the case that the predicate has satisfaction conditions, and for each predicate which is endowed with satisfaction conditions in this manner, there would be facts concerning the inclinations of the community that would make it the case that the predicate is (or is not) satisfied by a given object. The problem for this position arises from the fact that it clashes with the characterisation of our predicative practice sanctioned by its rules. A skilful construal of satisfaction in terms of our inclinations could certainly make the verdicts currently endorsed by the community come out right. But this vindication of communal inclinations would not really do justice to the conception of the practice that we feel inclined to endorse. For it is a central component of this conception that the verdicts on which communal consensus 
has been secured might be subsequently rejected in light of changes in our inclinations. As Wright himself admits, it is 'a fact about our procedure [...] that we make use of the notion that we can all be wrong'. ${ }^{46}$ We feel inclined to treat as correct the verdicts on which there is communal consensus, but we also feel inclined to treat those verdicts as revisable. In making the former aspect of our conception of the practice correct by definition, a Wright-style construal of satisfaction would force us to give up the latter.

This conflict between the conception of the practice that we feel inclined to endorse and the conception that would arise from an anti-realist construal of satisfaction raises the question of how the demand for revision could be supported. Since the rules that govern the practice sanction a conception according to which communal verdicts are revisable, a characterisation of the practice that renders them irrevisable would have to be grounded on the idea that there are constraints external to the practice which determine which of our verdicts are correct. These external constraints would dictate that, contrary to how we feel inclined to characterise our practice, our inclinations are answerable to how the community feels inclined to respond. Only by invoking such external constraints could the anti-realist justify his rejection of this aspect of our conception of the practice. But in so doing he would abandon his commitment to Wright's picture. $^{47}$

In order to avoid this conflict with the conception of the practice sanctioned by our inclinations, anti-realists could try to modify this basic construal of satisfaction by introducing the idea that satisfaction facts change whenever the community revises one of its verdicts. On this modified construal, if the community decides to revise its earlier verdict that a predicate is satisfied by an object, the object will no longer satisfy the predicate. And if we decide to revise our verdict that a predicate has satisfaction conditions, the predicate will cease to have satisfaction conditions. ${ }^{48}$

But this modification would fail to bring the anti-realist construal of satisfaction in line with the conception that the practice sanctions. According to this conception, many revisions of the verdicts of the community do not change the facts about satisfaction, but only our views on the matter. On the modified construal, when the community rejects its earlier verdicts, it shouldn't see itself as having been wrong until the revision took place. The verdict was correct while the community endorsed it. It became incorrect only when the community decided to reject it. But this is not the way in which the practice treats all revisions of communal verdicts. We often want to say that a verdict that we have rejected was wrong all along, in spite of our earlier unanimous inclination to endorse it. We conclude that a predicate lacks satisfaction conditions and that it never had them, even though we used to think that it did, or that a predicate was never satisfied by a given object, even though we used to agree that it was.

Another way in which we could try to reconcile a Wright-style construal of satisfaction with the conception of the practice that we feel inclined to endorse would be to construe satisfaction facts, not in terms of the verdicts on which there is communal consensus at the moment, but in terms of those on which there

(C) Blackwell Publishers Ltd. 2000 
would be consensus under certain ideal conditions. This manoeuvre would make room for revisions of community-sanctioned verdicts that leave satisfaction facts unchanged.

What should be said about this proposal depends on how the appeal to ideal conditions is understood. Satisfaction could be construed, on the one hand, in terms of conditions that are as a matter of fact ideal. But taking this route would involve an undisguised appeal to external standards, in direct contradiction with Wright's picture of the practice. On the other hand, satisfaction could be construed in terms of the verdicts that we would feel inclined to emit under the conditions that we now consider ideal. But this proposal would face a version of the difficulty that I have raised against other anti-realist construals of satisfaction. For we think of our verdicts concerning which conditions are ideal as no less revisable than the rest of the verdicts that we feel inclined to endorse. However, in construing satisfaction in terms of these verdicts, the present proposal would render them correct by definition. This means that, like its predecessors, this proposal would be in conflict with the conception of the practice sanctioned by our inclinations. Hence vindicating it would require appealing to external constraints governing the practice from outside, i.e. rejecting Wright's picture. At this point one might feel tempted to construe satisfaction in terms of the verdicts that we would feel inclined to emit under the conditions that we would consider ideal under ideal conditions. But this desperate move would obviously face a version of the same difficulty.

Let's turn now to the eliminativist position concerning satisfaction, according to which all our predicates lack satisfaction conditions. Notice that this claim is in direct conflict with the description of the situation sanctioned by the rules of our predicative practice. Engaging in the practice involves answering satisfaction questions according to our inclinations. We feel inclined to treat many of our predicates as having satisfaction conditions, and for the predicates that we feel inclined to treat in this way, we have inclinations concerning which objects satisfy them. This means that eliminativism faces the same difficulties as anti-realism. The problem emerges, once more, when we consider how the eliminativist position could be supported. If the use of the expressions with which satisfaction questions are formulated were governed by the rules of our predicative practice, then the answers that we feel inclined to give would have to be treated as correct. They would certainly be open to revision in the light of changes in our inclinations - we could subsequently come to the conclusion that some of them are wrong, but they would still be the right answers to give at this point. Hence, if we take on board the idea that our predicative practice is self-contained, not subject to any constraints other than our inclinations, as articulated by the rules of the practice, then we are bound to take eliminativism as incorrect. We would have to insist that many of our predicates have satisfaction conditions, even though our impression that they do may turn out to be incorrect.

The eliminativist may protest that his characterisation of the practice is faithful to Wright's picture. For he doesn't characterise our verdicts as subject to any constraints external to the practice. On the contrary, he characterises them as 
subject to no constraints at all. Nevertheless, eliminativism does involve a less direct appeal to external constraints. For the eliminativist, we are wrong in thinking that our predicates have satisfaction conditions. He believes that things are not as they would have to be in order for that thought to be correct. Hence, he has to support his position by appeal to constraints on what things would have to be like in order for our predicates to have satisfaction conditions. These constraints would determine whether our predicates have satisfaction conditions independently of whether we feel inclined to say that they do. Eliminativism would have to be supported on the grounds that those higher-order external constraints that determine which of our predicates have satisfaction conditions are not met by any of them. This means that eliminativism would rest, after all, on the very idea that Wright's picture rejects. Accepting this characterisation would involve saying, against the eliminativist, that many of our predicates have satisfaction conditions which determine which of our inclinations concerning their application are correct.

The outcome of this discussion is that commitment to Wright's picture would have to be accommodated in different ways depending on whether our task is to characterise an alien practice or our own predicative practice. In the case of the Martian labelling practice, the picture would have to be accommodated either by an eliminativist characterisation or by a Wright-style construal of correctness in terms of the Martians' inclinations. However, in the case of our predicative practice, both these strategies would rest on the rejection of Wright's picture, as they could be supported only by appeal to external standards governing the practice from outside. In this case, commitment to Wright's picture would require treating the practice at face value, by endorsing the characterisation that it sanctions. But this characterisation is unequivocally realist, as it treats many of our predicates as having satisfaction conditions whose existence and identity are independent of our inclinations concerning them. We have seen that the disanalogy results from the fact that, whereas the Martian practice is not in any way connected to the practice from which the characterisation is supposed to emerge, our predicative practice is (a central part of) our practice of representing the world in its different aspects, from the shapes and colours of the physical objects in our surroundings to the linguistic practices in which we engage.

8.

We are now in a position to cast some light on McDowell's metaphor. My proposal is to understand the contrast between characterising our linguistic practices from the cosmic exile's perspective and doing so from the midst of language as a going concern, in terms of the difference between the task of characterising the Martian labelling practice and that of characterising our own predicative practice. A characterisation of our predicative practice from the midst of language as a going concern would result from engagement in the very same practice that we are trying to characterise, while a characterisation from the cosmic exile's

(C) Blackwell Publishers Ltd. 2000 
perspective, just as our characterisation of the Martian practice, would not be a product of the practice that we are trying to characterise. When we construe the contrast in these terms, it is easy to see why a sense-making characterisation of our predicative practice could be provided only from the midst of language as a going concern (Claim 1), as the identity of the practice that yields the characterisation with the practice that we are trying to characterise places us automatically in that internal perspective. When we take ourselves to be characterising the practice from the cosmic exile's perspective, we are only failing to take account of this unavoidable identity. Representing our own representational practices is something that we can only do from within.

We can also make sense now of McDowell's contention that, if Wright's picture is true, it is a transcendental truth. According to Wright's picture, our predicative practice is not subject to any constraints other than our inclinations concerning the satisfaction conditions of predicates. But we have seen that these inclinations favour a realist conception of predicate satisfaction: some of our predicates have satisfaction conditions, and these satisfaction facts are not reducible to our inclinations. This is what we would say when we are characterising the practice from the midst of language as a going concern (Claim 2). This means that commitment to Wright's picture requires embracing realism. Attempting to express our commitment to Wright's picture with an anti-realist account of satisfaction would reveal, instead, a commitment to rejecting the picture, as an anti-realist account could be supported only by appeal to standards that govern the practice from outside. Someone who is committed to Wright's picture should say that realism is correct.

9.

The contrast with transcendental realism is much more elusive. The proponent of the middle position would want to agree with the transcendental realist only in how our linguistic practices should be characterised from the midst of language as a going concern. But in light of his view that this is the only perspective from which these practices can be characterised (Claim 1), it is hard to see how he can avoid the conclusion that he is in complete agreement with the transcendental realist - that their positions are indistinguishable.

To be sure, the transcendental realist and the proponent of the middle position reach their shared characterisation of our linguistic practices from the midst of language as a going concern from what seem to be entirely different routes. The proponent of the middle position endorses empirical realism as a consequence of his commitment to transcendental idealism - to the view that there is nothing but verbal behaviour and feelings of constraint underlying our linguistic practices. The transcendental realist would oppose to this a different account of why empirical realism is correct. On this account, the reason why we are right in embracing the characterisation of our predicative practice sanctioned by our inclinations is 
that there really are language-world connections underlying the practice, from which predicates obtain the standards that determine which objects satisfy them. For the transcendental realist, the reason why empirical realism is correct is not that we cannot adopt a vantage point external to our practices from which their correctness could be adjudicated. Empirical realism is correct because of how things look from that external vantage point. We are right in thinking that some of our predicates have satisfaction conditions that are not reducible to our inclinations because each of them is connected with a property whose instantiation conditions determine which objects satisfy the predicate.

The difficulty lies in translating this intuitive contrast between their motivations into an actual disagreement. For the proponent of the middle position seems committed to endorsing every claim with which the transcendental realist might want to represent his position. The proponent of the middle position would join the transcendental realist in asserting the existence of genuine language-world connections from which our predicates obtain their satisfaction conditions, pointing out that in making this claim we are only reformulating our commitment to the description of the practice sanctioned by our inclinations. For saying that there is a feature of the world on whose presence in an object the applicability of a predicate depends is just another way of saying that the predicate has satisfaction conditions.

The proponent of the middle position would even concede that we can make sense of the idea of considering how things look from outside the practice - of distancing ourselves from the inclinations that we associate with predicates to determine whether there really are satisfaction facts with respect to which our predicate ascriptions are correct or incorrect. And for the proponent of the middle position, insofar as we can adopt this detached point of view, we will come up with a realist verdict. He would add that asking what things would look like from outside the practice is as much a part of the practice as the more 'internal' verdicts that we take ourselves to be vindicating from that external vantage point, since the characterisation of the connections between our language and the world is only an aspect of the overall enterprise of representing the world. Hence he would see the verdicts that we reach when we try to represent (with our language) semantic aspects of reality as no less dependent on the inclinations on which the practice is built than the verdicts that we reach when we are trying to represent any other region of the world. However, we can't hope to locate in this gloss the contrast between the middle position and transcendental realism, as it is hard to see how the transcendental realist could fail to endorse it.

The proponent of the middle position could contend at this point that our failure to identify an issue on which he and the transcendental realist would take different sides should not be counted as undermining his position. He would refuse to represent his dispute with the transcendental realist as a matter of choosing between two alternative coherent positions. He would argue that his is the only intelligible version of realism, and that those who see themselves as endorsing a version of the position which goes beyond what he is prepared to accept are simply confused. ${ }^{49}$

(C) Blackwell Publishers Ltd. 2000 
Taking this line would amount to endorsing Davidson's contention that transcendental realism, seen as a genuine alternative to the middle position, isn't wrong, but incomprehensible. The transcendental realist may feel that the attempt by the proponent of the middle position to co-opt his views fails to grasp an essential ingredient of the position - that in endorsing the claims with which the transcendental realist tries to characterise his position, the proponent of the middle position down-grades the commitment to real language-world connections that these claims are meant to express. But his complaint is invalidated by his failure to identify an aspect of this commitment that the proponent of the middle position would not accept. The proponent of the middle position could now point to this failure as what makes Wright's picture the right account of how things would look from the cosmic exile's perspective (Claim 3).

Nevertheless, the transcendental realist could take exception to this attempt at representing the middle position as victorious, throwing back at the middle position the charge of unintelligibility. For the claim that transcendental realism adds nothing intelligible to what the proponent of the middle position is prepared to accept can be reformulated as the claim that the middle position subtracts nothing intelligible from what the transcendental realist wanted to say. If the proponent of the middle position wants to represent himself as going right where others go wrong, the onus is on him to identify an aspect of transcendental realism that he doesn't accept, but his attack on transcendental realism is based precisely on the contention that this cannot be done.

At this point the dispute between transcendental realism and the middle position seems to dissolve into the bland remark that different people come to find realism appealing through different images and intuitions. ${ }^{50}$ And this outcome would leave the distinct impression that the middle position has failed to make a significant contribution to the realist cause.

Notice that we have reached this impasse because the proponent of the middle position can't seem to find any opponents in the realist camp, since nothing that a realist could say would mark him as committed to the brand of realism that the proponent of the middle position considers unintelligible. This suggests that we might be able to rescue the dispute between the middle position and transcendental realism if we could find a way in which this commitment can be manifested-a way, to use McDowell's Tractarian image, in which an empirical realist could show where he stands on the transcendental question. I would like to end by briefly considering two proposals as to how this goal might be attained.

10.

The first proposal that I want to consider is that a realist's stance on the transcendental question might be manifested by his attitude towards the demand for an account in non-semantic terms of the relation which pairs each predicate with the property that determines its satisfaction conditions. For the transcendental realist, our entitlement to irreducible satisfaction facts is subject to the existence 
of a relation between predicates and properties from which predicates obtain their satisfaction conditions. Hence vindicating irreducible satisfaction facts would require showing that one of the relations that predicates bear to properties can actually play this role. For the proponent of the middle position, by contrast, our entitlement to postulating irreducible satisfaction facts is not subject to whether we can find a relation that plays this role. Our entitlement to this claim emerges instead from the reflection that it is only from the point of view of the inclinations underlying the practice that the claim can be adjudicated. From this point of view, the search for the predicate-property relation that gives rise to satisfaction facts would be a pointless project. This suggests that the demand for an account in non-semantic terms of the relation with properties from which predicates obtain their satisfaction conditions provides a positive test for transcendental realism, as it manifests a commitment to the characterisation of our practices from the cosmic exile's perspective that the middle position rejects. ${ }^{51}$

I shall not try to provide a definitive assessment of this proposal, but I would like to present a major challenge that it faces. The problem is that it is far from clear that the project of providing a non-semantic account of the relation from which satisfaction facts arise can be motivated only by invoking the transcendental realist picture. The point was made by Hartry Field, in his defence of naturalistic theories of semantic notions against the repudiation of the cosmic exile's perspective that he finds in Quine. 'In looking for a theory of truth and a theory of primitive reference', Field writes, 'we are trying to explain the connection between language and (extralinguistic) reality, but we are not trying to step outside our theories of the world in order to do so' ${ }^{52}$ Field's point is that naturalistic accounts of semantic notions are called for by the conception of language and its relation to the world that we get 'from the midst of language as a going concern':

The reason why accounts of truth and primitive reference are needed is not to tack our conceptual scheme onto reality from the outside; the reason, rather, is that without such accounts our conceptual scheme breaks down from the inside. On our theory of the world it would be extremely surprising if there were some non-physical connection between words and things. Thus if we could argue from our theory of the world that the notion of an utterer's saying something true, or referring to a particular thing, cannot be made sense of in physicalist terms [...], then to the extent that such an argument is convincing we ought to be led to conclude that, if we are to remain physicalists, the notions of truth and reference must be abandoned..$^{53}$

I shall not try to decide here whether Field is right in thinking that physicalism rules out the existence of semantic facts for which no account in physicalistic terms can be provided. ${ }^{54}$ But unless the line of reasoning advanced by Field can 
be exposed as involving a tacit appeal to the cosmic exile's perspective, the demand for naturalistic accounts of semantic notions will not provide a test for transcendental realism: Insofar as our inclinations sanction a physicalistic theory of the world, we will have to subscribe to the demand, independently of where we stand on the transcendental question.

11.

The second proposal that I'd like to consider consists in looking for a manifestation of the contrast between the middle position and transcendental realism in the attitude that we are entitled to adopt towards the traditional sceptical challenge to our justification claims. Our predicate ascriptions are a natural target for the sceptic, since our verdicts on whether an object satisfies one of our predicates seem to be ultimately based on ungrounded inclinations. It is easy to see how the sceptic could use this observation to run his standard line of reasoning. He would demand an argument to bridge the gap between the ungrounded inclinations on which our verdicts are based and the satisfaction facts which render our verdicts correct or incorrect. And he would insist that his challenge won't be met unless the argument we come up with doesn't invoke an assumption to the effect that our inclinations are reliable. If we couldn't satisfy this demand, the sceptic would urge us to treat our preference for the predicate ascriptions sanctioned by our inclinations as unjustified prejudice. And since predicate ascriptions play a central part in our belief system, this would force us to give up virtually all our justification claims.

According to the proposal that I am considering, a realist's stance on the transcendental question would be manifested by the position in which he finds himself with respect to this challenge. For the transcendental realist, the satisfaction conditions of our predicates are determined by a relation to the world which is fundamentally independent from our predicative practice and the inclinations on which it rests. This raises the question whether our inclinations track satisfaction facts to any degree. And an affirmative answer to this question would have to be supported by the kind of argument that the sceptic calls for. We would have to show that whether our inclinations sanction the ascription of a predicate to an object is a reliable indicator of whether the object satisfies the predicate, as determined by the predicate-property relation which constitutes satisfaction facts, on the transcendental realist picture. And to establish this conclusion we wouldn't be entitled to presuppose in any way the reliability of the inclinations that we are trying to vindicate. If this task couldn't be accomplished, we would have to concede defeat to the sceptic, accepting that our predicate ascriptions are entirely unjustified.

The proponent of the middle position would fully endorse the characterisation of our predicative practice that gives rise to the sceptic's challenge. He would accept that our predicate ascriptions rest, in the end, on ungrounded inclinations, 
and that, since satisfaction facts are independent of these inclinations, our predicate ascriptions might fail to track satisfaction facts as radically as the sceptic suggests. In fact, he wouldn't rule out the possibility that we come to see things this way. We might come to the conclusion that most or all of the predicate ascriptions currently sanctioned by our inclinations are actually wrong, or even that our most fundamental procedures for deciding on the ascription of predicates (e.g., ascribing predicates such as 'green', 'square' or 'table' on the basis of sensory experience) are utterly unreliable.

However, for the proponent of the middle position, accepting this characterisation of our predicative practice doesn't render the justification of our predicate ascriptions hostage to the availability of the kind of argument that the sceptic demands. According to the middle position, the rules of the practice dictate that we should endorse the predicate ascriptions currently sanctioned by our inclinations. We might later conclude that these verdicts were wrong, but this possibility doesn't undermine their status as the verdicts that we should endorse at this point. In taking this stance, the proponent of the middle position is not refusing to entertain justification questions. He can concede that we can genuinely ask to what extent our predicate ascriptions track satisfaction facts, but he will add that trying to answer questions of this kind is just another aspect of the practice - no less so than trying to decide whether to ascribe a predicate to an object. And what goes for 'first-order' questions concerning the ascription of a predicate to an object goes for questions concerning the justification of our first-order verdicts. The rules of the practice dictate that we should endorse the answers to justification questions currently sanctioned by our inclinations. Once again, we could conclude later that these answers were wrong that the predicate ascriptions that we considered justified are actually unjustified - but this possibility doesn't undermine the status of the justification claims that our inclinations currently sanction as the claims that we should endorse at this point. This means that the proponent of the middle position will feel entitled to reject the terms of the sceptical challenge. He will see nothing wrong with invoking in our justificatory arguments our conception of the relationship between the procedures that we employ for deciding on the ascription of predicates and the features of the world that we take our predicates to represent, even though this conception incorporates the predicate ascriptions currently sanctioned by our inclinations.

The proposal is then that taking the sceptic's challenge at face value would manifest a commitment to transcendental realism, whereas rejecting the terms of the challenge would manifest a commitment to the transcendental stance built into the middle position. An assessment of the merits of this proposal is beyond the scope of this paper. Vindicating it would require, among other things, showing that the attitude to the sceptic's challenge that I have attributed to the middle position doesn't undermine its realist credentials. But if the proposal were found acceptable, it would provide not only a way of rescuing the dispute between the middle position and transcendental realism. It would also make the middle position appear appealing to those who think that the sceptic's challenge cannot be

(C) Blackwell Publishers Ltd. 2000 
met, but refuse to countenance the conclusion that the sceptic draws from this failure. ${ }^{55}$

\section{José L. Zalabardo}

Department of Philosophy

University of Birmingham

Edgbaston

Birmingham B15 2TT

England

e-mail: j.l.zalabardo@bham.ac.uk

\section{NOTES}

1 Davidson 1990: 304.

2 ibid.

3 Davidson 1990: 308-309.

4 Putnam 1994: 494.

5 Putnam 1994: 516-17. Davidson thinks now that he once mistakenly made a similar assumption: 'I simply made the mistake of assuming realism and epistemic theories were the only possible positions' (Davidson 1990: 304).

6 Putnam 1994: 509.

7 ibid.

8 McDowell 1984, esp. §12.

9 McDowell's immediate target is the interpretation of Wittgenstein's views that Wright develops in Wittgenstein on the Foundations of Mathematics.

10 McDowell 1984: 336.

11 Notice that on this construal of the range of possible accounts of predicate satisfaction there is an important difference between theories in which speakers' propensities figure only as determining which particular predicate ascriptions speakers feel inclined to endorse and theories in which speakers' dispositions single out the property which determines the satisfaction conditions of each predicate. The label 'anti-realist' may have been used for both kinds of theory, but here I am applying it exclusively to the former kind.

12 McDowell 1984: 353.

13 ibid.

14 op. cit., p. 336

15 ibid.

16 op. cit., p. 347.

17 op. cit., p. $352-53$.

18 op. cit.., p. 353.

19 cf. ibid.

20 op. cit., p. 348.

21 op. cit.., p. 353.

22 op. cit., p. 352.

23 op. cit., p. 341.

24 ibid.

25 op. cit., p. 350. 
26 ibid.

27 Field 1972: 358.

28 ibid.

29 In the first edition of Realism and Truth, Michael Devitt characterises McDowell's version of Davidsonian semantics as involving a semanticalist component (cf. Ch. 10). In the second edition he shifts towards a different characterisation of McDowell's views.

30 McDowell 1981: 248.

31 ibid.

32 ibid.

33 McDowell 1981: 237ff.

34 McDowell 1981: 248.

35 ibid.

36 ibid.

37 The characterisation of the views of the later Wittgenstein as a form of transcendental idealism can be traced back to Bernard Williams' 'Wittgenstein and Idealism'. In 'Leaving the World Alone', Jonathan Lear invokes the transcendental character of Wittgenstein's idealism to question the Wittgensteinian credentials of anti-realist positions.

38 McDowell 1981: 248.

39 ibid.

40 ibid.

41 Lear expresses in similar terms his objections to positions that make truth dependent on our inclinations: 'As we try to stretch ourselves to say something philosophical, we end up saying things that are, strictly speaking, false' (1982: 385).

42 See $\$ 9$, below, on the relationship between platonism and transcendental idealism.

43 I am not claiming that this reading of the spatial metaphor of 'Wittgenstein on Following a Rule' (McDowell 1984) would be faithful to McDowell's intentions. More likely, the change of metaphors corresponds to a change of views, and by the time McDowell wrote 'Wittgenstein on Following a Rule' he thought that refusing to countenance sub-'bedrock' characterisations of semantic notions was all he needed to do in order to occupy a middle position (cf. McDowell 1987, in which a middle position is characterised in essentially the same terms). But I have argued that this wouldn't yield a genuine middle position, as the resulting view would be indistinguishable from the semanticalist version of platonism.

44 cf. Dummett 1973: 295-298.

45 I am indebted on this point to an anonymous referee for this journal.

46 Wright 1980: 219-220.

47 cf., in this connection, Rosen 1994. Rosen contends that treating the central concepts of a discourse as response-dependent or judgment-dependent does not detract from the objectivity of the facts that the discourse represents.

48 Wright (1986) seems to acknowledge that semantic facts can change with the propensities that underlie our use of language: cf. pp. $289 \mathrm{ff}$.

49 This position is germane to the defence of transcendental idealism that José Luis Bermúdez has offered on Kant's behalf. cf. Bermúdez 1995: 18-23. Bermúdez's proposal is to defend transcendental idealism by arguing that the transcendental realist (and by extension the sceptic) cannot coherently suggest that there might be a noumenal world containing noumenal objects' (p. 21; Bermúdez later introduces an important qualification of this statement).

50 Simon Blackburn (1980) seems to endorse this characterisation of the dispute.

51 Notice that the reflection of this demand cannot be seen as manifesting a commit-

(c) Blackwell Publishers Ltd. 2000 
ment to transcendental idealism, as a semanticalist would also reject the demand, and we wouldn't want semanticalism to entail transcendental idealism.

52 Field 1972: 373.

53 ibid.

54 On this point, see McDowell's response to Field's article in McDowell 1978. See also McDowell 1994, esp. Lecture IV, where he rejects the equation of nature with the realm of law.

55 I am indebted to Rob Hopkins, Harold Noonan, Jim Stuart, Crispin Wright and, especially, to the late Barrie Falk.

\section{REFERENCES}

Bermúdez, J. (1995), 'Scepticism and the Justification of Transcendental Idealism', Ratio (New Series), vol. 8, pp. 1-23.

Blackburn, S. (1980), 'Truth, Realism, and the Regulation of Theory', in P. French et al. (eds.), Midwest Studies in Philosophy, vol. V: Studies in Epistemology. Minneapolis: University of Minnesota Press.

Davidson, D. (1990), 'The Structure and Content of Truth', Journal of Philosophy, vol. 87, pp. 279-328.

Devitt, M. (1984), Realism and Truth. Oxford: Blackwell (2nd Ed. 1991).

Dummett, M. (1973), Frege: Philosophy of Language. London: Duckworth.

Field, H. (1972), 'Tarski's Theory of Truth', Journal of Philosophy, vol. 69, pp. 347-375.

Lear, J. (1982), 'Leaving the World Alone', Journal of Philosophy, vol. 79, pp. 382-403.

McDowell, J. (1978), 'Physicalism and Primitive Denotation: Field on Tarski', Erkenntnis, vol. 13, pp. 131-52.

McDowell, J. (1981), 'Anti-Realism and the Epistemology of Understanding', in M. Parret and J. Bouveresse (eds.), Meaning and Understanding. Berlin-New York: de Gruyter.

McDowell, J. (1984), 'Wittgenstein on Following a Rule', Synthese, vol. 58, pp. 325-363.

McDowell, J. (1987), 'In Defence of Modesty', in B. Taylor (ed.), Michael Dummett: Contributions to Philosophy. Dordrecht: M. Nijhoff.

McDowell, J. (1994), Mind and World. Cambridge, Mass.: Harvard University Press.

Putnam, H. (1994), 'Sense, Nonsense and the Senses: An Inquiry into the Powers of the Human Mind', Journal of Philosophy, vol. 91, pp. 445-517.

Rosen, G. (1994), 'Objectivity and Modern Idealism: What Is the Question?', in M. Michael and J. O'Leary-Hawthorne (eds.), Philosophy in Mind. Dordrecht: Kluwer.

Williams, B. (1974), 'Wittgenstein and Idealism', in Godfrey Vesey (ed.), Understanding Wittgenstein, Royal Institute of Philosophy Lectures 1972-73. London: Macmillan.

Wright, C. (1980), Wittgenstein on the Foundations of Mathematics. London: Duckworth.

Wright, C. (1986), 'Rule Following, Meaning and Constructivism', in C. Travis (ed.), Meaning and Interpretation. Oxford: Blackwell Publishers. 